\author{
sit \\ Towards a philosophy of energy \\ Robert-Jan GeERTS \\ Bart Gremmen \\ Josette JАСовS \\ Guido Ruivenkam P
}

\begin{abstract}
$\stackrel{\sim}{\dddot{2}}$
ABSTRACT

Transition to a sustainable energy regime is one of the key global societal challenges for the coming decades. Many technological innovations are in the pipeline, but an uncritical appraisal of anything and everything called green innovation lacks methods for testing both the necessity and the sufficiency of these developments. We propose to develop a philosophy of energy to fill this lacuna. Its task is to explore and clarify the space in which the so-called energy transition is taking place. This article sketches the fundaments of such a philosophy and suggests how it might be built upon the work of twentieth century critics of the functioning of energy in society, including Mumford, Bataille, and Heidegger; but not without empirical analysis of contemporary energy systems. Via the example of flux and potentiality - two apparently opposing conceptions of energy - we propose that a philosophy of energy allows for a broader perspective on specific problems in energy transition, and illuminates implicit and problematic assumptions behind these problems.
\end{abstract}

KEYwords $\bullet$ Philosophy of energy. Energy transition. Sustainability. Renewable energy. Mumford. Bataille. Heidegger.

\title{
INTRODUCTION
}

The functioning of Western society is currently vitally dependent on the combustion of fossil fuels for energy. This energy is used for transportation, heating, the production of food and consumption articles, and a myriad of other things. Two developments threaten this dependence: anthropogenic climate change and the depletion of easily accessible fossil fuel stocks. In recent years, these twin problems have sparked an enormous array of innovations: from energy efficiency improvements to renewable electricity sources, and from biofuels to cycling infrastructure. These innovations do not all represent solutions to the same problem, but are generally assumed to work towards the common goal of a sustainable energy regime. Developments towards this novel situation collectively make up an energy transition (cf. Kern \& Smith, 2008). 
The fact that people are working on so many different solutions to so many different problems relating to energy transition typically gets positively perceived. With our dependence on (fossil) energy so all-encompassing, relying on a single "silver bullet" technology would be both naïve and risky (cf. MacKay, 2009). Instead, it would seem better to spread our chances and develop a range of technologies that cumulatively and sufficiently reduce our dependence on fossil fuels and also reduce $\mathrm{CO}_{2}$ emissions. This line of reasoning has resulted in a situation in which "green" innovations crop up everywhere: from new types of photovoltaic cells to airlines bragging about running their ground vehicles on biofuels. However, an uncritical appraisal of anything and everything called green innovation lacks methods for testing both the necessity and the sufficiency of these developments. We may currently outline two lines of critique against green developments.

The first might be described as the "greenwashing police" - contesters of specific innovations, who critically assess the quality of the "green" claims made by developers. Are they actually true? Do they deal with the most pressing problems? In the case of the airline ground vehicles for example, one could claim that the focus on renewable energy for ground vehicles serves only to deflect attention from the much larger energy consumption of the airplanes that these companies operate. This strategy is limited in scope: whilst raising questions on what we understand as proper green technologies, the approach does not prove appropriate to answering those questions. It sticks to the hard facts, and works in the language of the technologists. This means that although able to engage in actual debate with the developers of novel technologies, this also means that the perspective sticks with the technologist framework: it will contest a misleading representation of vehicle mileage but leave car culture as it is.

The second line of critique works through social science and emphasizes "soft" impacts of energy technologies. Anthropological accounts, for example, describe how electrification shapes life in remote villages, sociology and science and technology in society (STS hereafter) scholars research how the location of wind farms is negotiated among stakeholders, thereby pointing to novel dimensions to the energy transition problem. This approach tends to focus on all that is left out of the technologist costbenefit analysis. Social scientists therefore use a language that is fundamentally different from that of technologists; this leads to technologists freezing up when societal aspects of the implementation of their plans come into play. Claims such as "we just provide the options, society decides which ones it will accept" are commonplace. Similarly, social scientists refrain from taking a position on any technical issue: for them, the whole exercise is one of social capital, actors and networks, and so forth. For example, when talking about the development of wind farms in Wyoming, Strauss and 
Reeser (2013) remain silent on differences between coal mining and wind farming. These technologies remain black-boxed in their analysis.

Neither of the problems with the two aforementioned lines of critique proves serious as long as we have a clear image of the problem, and we assume independent development of society and technology. However, in practice, this is hard to accept: energy transition represents a messy project with a broad variety of goals and, within STS research; that there is at least some kind of co-development of technology and society no longer gets contested. Furthermore, in the case of energy this becomes particularly obvious: industrial society with all its benefits would never have been possible without ample and inexpensive energy sources (cf. Wrigley, 2010; Sieferle, 2010 [1982]).

From a theoretical standpoint, we might now suggest that the two current approaches to critiquing the energy transition project seem to leave a gap in their strategies. If goals are not clear and there is a co-development of technology and society, then there might be an area of critique running deeper than the mere critique of particular technologies, remaining closer to the intricate connections between technology and society, and therefore more reflective than technological approaches and more technical than current social science approaches. We believe this area belongs to the philosophy of energy.

This claim immediately raises two questions: why philosophy, and why a specific and new branch of philosophy? We hold that philosophy's conceptual analysis, critical reflection on argumentation, and its ability to raise the level of abstraction, provide exactly the clarity that is currently lacking in the debate. In addition, by drawing from a broad range of sources, more-or-less continental approaches to philosophy can introduce new concepts and perspectives to the debate in order to open up the playing field. This constitutes the kind of creative philosophy that we seek. Furthermore, the specificities of energy and energy technologies are central to the current lack of clarity, so any philosophical insight must be firmly grounded in a proper understanding of energy. Without this, it will be impossible to create relevance for actual energy-related problems, and to appeal to the engineers and policymakers who are shaping the energy transition. This article represents an attempt to establish this field, locating it amongst its theoretical neighbors and identifying its roots and ancestors. We compare and contrast the philosophy of energy to these fields, and defend the position that this indeed entails a distinct niche that comes with its own specific perspective that is not, and cannot be, adequately addressed by any other field. The article concludes with an example of the kind of issue susceptible to better understanding via our approach. 


\section{Philosophies of energy}

This is not the first attempt at philosophizing about energy. Indeed, there are at least three lines of thought to be found in history dealing to a greater or lesser extent with aspects of energy:

(1) the inquiry into the natural phenomenon of energy;

(2) the critique of the functioning of energy in society;

(3) the philosophy of technology.

All three lines of thought contribute essential ingredients to a fully-fledged philosophy of energy: the first two can be seen as attempts to develop philosophies of energy in their own right, whereas the third guides us towards a more fruitful level of analysis for issues relating to the current energy transition. In this section, we introduce the first two of these lines, but would first emphasize that we take some liberties in our reading of these thinkers in order to build upon them and, as we are specifically looking for philosophies of energy, we do not approach these texts neutrally.

\subsection{INQUIRY INTO THE NATURAL PHENOMENON OF ENERGY}

Inquiry into the natural phenomenon of energy stretches back to Heraclitus (c. $5^{3} 5^{-}$ c. 475 a.C.) and Aristotle (384-322 a.C.). Whereas the former allegedly argued that everything changes, the latter noticed that this was not exactly true: although change happens, a lot of things also stay the same. The energy historian R. Bruce Lindsay suggests that, from Aristotle onwards, an unbroken line of inquiry into the concept of energy can be drawn all the way to Einstein, with as common denominator the assumption that "the root of the concept is the notion of invariance or constancy in the midst of change" (Lindsay, 1971, p. 383). The domain of these inquiries steadily expanded from mechanical questions on the functioning of levers and pulleys through to thermodynamic phenomena such as combustion, electromagnetism, and the discovery of massenergy equivalence in the early twentieth century.

We do not need to reiterate this history in any detail here; what is important here involves realizing the exceptional breadth of phenomena that are fruitfully connected with the concept of energy. Over time, these insights have led to increasingly complex technologies for converting one kind of energy into another. windmills convert the linear movement of air into a rotating movement, steam engines convert chemical energy into a rotating movement via heat and pressure, solar panels convert the energy in sunlight into electricity, and, in our homes, our appliances convert electricity back into 
movement, light, heat, and sound. Arguably, all our activities are understandable simply in terms of converting one kind of energy into another.

The universality of the energy concept does not merely extend to a number of fields in science; it also provides a running thread in the production of other resources. The scarcity of food, drinking water, minerals, transportation capacity, and all kinds of produced goods are all to a greater or lesser extent bound up with the price or availability of energy. There are ways to produce or access more of these goods, but this would involve higher energy expenditure. This is why technologists get so excited when new and apparently infinite energy sources are introduced. In the heyday of nuclear energy, Weinberg (1967), for example, suggested that desalination of sea water would make arid areas all over the world productive, whilst nuclear-powered air traffic would make flight accessible to all. We now know things developed otherwise, but the appeal and importance of developments in energy remain as strong as ever. ${ }^{\mathbf{1}}$

There is a specific understanding of energy underpinning all these developments: a quantitative, abstract concept of "the ability to do work" that mutually interconnects a broad range of physical phenomena. This is the first philosophy of energy that we encounter, and most present-day natural scientists subscribe to some similar form of understanding energy. Although the unification of physical phenomena via the concept of energy has been exceptionally successful, conflicting conceptions of energy do exist. These conceptions are also the result of inquiry into the natural phenomenon of energy, but, rather than relating to the scientific, quantitative paradigm, they appeal to qualitative approaches. As Hein van Dongen (2013) notes, the exploration of the natural scientists obscures the non-exact phenomenon of "life energy", related to the oriental idea of qi: the immanent energy in social relations. This is what Stephanie Rupp (2013) found when interviewed New York City citizens came up with phrases like "the energy of the city", and what Van Dongen noticed when a team of exhausted soccer players could be re-energized by a sudden goal late in the game (cf. Van Dongen, 2013, p. 37). Although on a biochemical level these experiences may share a unified physical theory with a power plant, understanding them in these terms does not prove very helpful.

Thus, there would be great relevance in ascertaining whether an overarching philosophy of energy would enable the reconnection of these two apparently disjoined conceptions of energy. At the very least, the qualitative conception of life energy hints at what the scientific understanding of energy could do for humanity: it reminds us of the reasons why we are interested in harnessing energy in nature: to work towards achieving our goals and expanding our abilities.

1 We now see a similar hype around bio fuels, whilst hovering in the background there is the expectation of nuclear fusion as the unproblematic energy source in the distant future. 
The scientific understanding of energy has enabled society to plug into ever increasing amounts of energy in various forms, but it fails to say much about the effects of these developments on society. After all, the physical understanding is distinctly lab based - only looking at the phenomenon of energy in isolation. We would note that it understands energy as a purely natural phenomenon, external to the level of society's control over it. This leads to a static conception of energy over time: we might improve our understanding of it, but energy itself remains the same no matter what we do with it. Something similar holds for inquiries into life energy: they are silent on energy external to the body. However, while this is not problematic in itself, should we seek to gauge what is changing in energy transition, a static understanding of energy falls short of the mark.

As changes in energy practices became increasingly visible and influential in industrial societies, in the late nineteenth century, an interest in energy emerged in the area that can broadly be described as social critique. In the twentieth century, this was picked up by a few great thinkers, and here we do find some ideas on how society relates to energy, and how this relationship developed throughout history. The following sub-section touches on three of these thinkers: Lewis Mumford, Georges Bataille, and Martin Heidegger.

\subsection{Critique of Energy in Society}

In his groundbreaking book Technics and civilization, Lewis Mumford (2010 [1934]) places energy usage squarely in the middle of his analysis of society. From his perspective, there are four steps in the functioning of energy in society: conversion, production, consumption, and creation. All energy we know originates from the sun, ${ }^{2}$ and solar energy is converted into food and fuels via photosynthesis. "This seizure of energy is the original source of all our gains: on a purely energetic interpretation of the process, all that happens after this is a dissipation of energy" (p. 375). Next to organic conversion, Mumford mentions mechanical conversion: water-wheels, steam engines, and so forth. These technologies opened up new sources of energy and allowed for "the gigantic scale [the apparatus of production and transport] attained in the nineteenth century" (p. 376). Production, then, involves the usage of converted energy to gather, transport, and shape raw materials into products, which are subsequently consumed by society. The final step - that of creation - is what everything really revolves around for Mumford.

2 This was before nuclear energy and geo-thermal energy became well-known. 
Not until the economic process reaches the stage of creation - not until it supplies the human animal with more energy than he needs to maintain his physical existence, and not until still other energies are transformed into the more durable media of art and science and philosophy, of books, buildings and symbols is there anything that can be called, even within a limited span of time, a gain (p. 376$)$.

Simply sustaining society is not enough. The goal of all our efforts must be to develop into something better, to create a lasting heritage of worthy cultural products such as art and science. This leads Mumford to a critique of capitalism. According to his position, the surplus energy that could be used for creation instead gets deployed for re-investment to increase production, which leads to the overexpansion of production facilities and correspondingly to efforts put into marketing and promotion in order to be able to sell all these superfluously produced goods. The reason behind this, as Mumford proposes: "there is no capitalist theory of non-profit-making enterprises and non-consumable goods" (p. 377). The few bits of "creation" that do occur, do so accidentally: there is no place for them within the system.

This disquiets Mumford, due to his belief that a society able to harness increasing amounts of energy should also be able to devote an increasing share of this to the things that actually matter. ${ }^{3}$ One does not have to share Mumford's position on capitalism to appreciate his more general insight as to how the availability of more energy does not automatically lead to either a better society or better lives lived within this society. Mumford drives this point home as follows:

The real significance of the machine, socially speaking, does not consist either in the multiplication of goods or the multiplication of wants, real or illusory. Its significance lies in the gains of energy through increased conversion, through efficient production, through balanced consumption, and through socialized creation. The test of economic success does not, therefore, lie in the industrial process alone, and it cannot be measured by the amount of horsepower converted or by the amount commanded by an individual user: for the important factors here are not quantities but ratios: ratios of mechanical effort to social and cultural results. A society in which production and consumption completely can-

3 Smil (2008) contests this. He maintains that more energy production leads to greater carrying capacity, but at the cost of a larger effort for its inhabitants: intensification of agriculture leads to declining energy return on energy investment (EROEI). The upshot of this is that intensification is ultimately self-defeating: it leads to higher energy levels, but less free energy (Smil, 2008, p. 148-9). 
celled out the gains of conversion - in which people worked to live and lived to work - would remain socially inefficient, even if the entire population were constantly employed, and adequately fed, clothed, and sheltered. The ultimate test of an efficient industry is the ratio between productive means and the achieved ends (Mumford, 2010 [1934], p. 378-9).

In Technics and civilizations, Mumford implicitly develops a philosophy of energy. He seems to subscribe to an instrumental position. Energy is a resource we can consume however we please, but we are not currently doing so in the best way imaginable. This position makes possible, and perhaps even requires, the additional development of an ethics of energy: if it is essentially a neutral instrument, there are better and worse ways of dealing with energy. It is clear that, for Mumford, the main target for an ethics of energy is to steer as much as possible towards creation.

The creation stage is still notably absent in current debates on energy transition. Implicitly it is assumed that whatever energy we can get hold of will be put to good use. In a recent article, Carl Mitcham and Jessica Smith Rolston (2013) problematized this assumption. They argue for an energy ethic that does not equate more energy with better lives, by pointing to historical data that show little growth in quality of life in the US in the second half of the twentieth century, even though energy consumption increased significantly. Although Mitcham and Rolston do not go into it, their approach raises questions regarding "good" energy consumption: is there really a ceiling to it? Is there a maximum creation-to-conversion ratio? Are there different levels of energy consumption at which we attain the same quality of life, by organizing society differently?

However, before plunging into such questions, we take a step back and move onto the work of Georges Bataille, who contests the instrumental conception of energy proposed by Mumford. In The accursed share, Bataille (1991 [1949]) suggests that our energy practices are not instrumental to satisfying our needs, but rather it is the other way around; satisfying our needs is a way of dealing with the excessive emission of energy by the sun. This reversal may strike the reader as far-fetched, but does contain some insights, as well as a number of striking parallels between Bataille's and Mumford's position and some statements in renewable energy projects.

Life, argues Bataille, has always been about abundance rather than scarcity. The surplus of abundant solar energy makes life possible and, over the course of evolution, life has found ways to consume increasing amounts of this energy. Every organism has, after using energy for its sustenance, access to a certain surplus, which is used either for growth or reproduction (which represents growth on the population level), leading to an accumulation of biomass. However, this process cannot proceed indefinitely; at some point, carrying capacity is reached, and it becomes impossible for a certain or- 
ganism to continue accumulating. "[T] his movement of growth runs up against limits at every stage of life. It is continuously stopped and forced to wait for a change in the conditions of life before resuming" (Bataille, 1991 [1949], p. 180). Two examples of such changes in the conditions of life referred to by Bataille are the development of trees (the tendency of plants to grow skywards to increase their photosynthetic surface) and the emergence of carnivores. The former is a way of life to increase accumulation potential, the latter is a means of burning off useless excess. Death is not strictly necessary for life, as infinitely dividing bacteria prove, but it is a way for life to burn off excess energy that cannot be used in a productive manner.

According to Bataille, the development of technologies by humanity must be understood in this light.

And similarly, once domination of the available space is ensured at the expense of animals, men have their wars and their thousand forms of useless consumption. Mankind is at the same time - through industry, which uses energy for the development of the forces of production - a manifold opening of the possibilities of growth and an infinite capacity for wasteful consumption (Bataille, 1991 [1949], p. 181).

Our growing energy production and consumption simply represent an extension of this natural tendency of life to look for ever increasing accumulation and niches to fill, and to burn off the excess when accumulation is not possible. As the reference to war in this quote suggests, this dynamic comes with a certain danger. The burn-off of excess often happens in violent ways, and, with our increasing capabilities to accumulate large amounts of energy, the burn-off events display an increasing intensity. Wars in the twentieth century were far more deadly and devastating than their predecessors in earlier centuries.

This problem only gets exacerbated by the capitalist ethic, which, as we have already noted, always aims to re-invest any surplus available, rather than expending it on lavish consumption. This has created a society with relatively few pressure valves in place for shedding accumulated excesses. As Bataille maintains that it is only a matter of time before our accumulative practices reach their limits, he believes we can only ever be heading towards another and even more violent war. Only understanding an economy from the general perspective of the cosmos - rather than that of particular players in that economy - can render this problem visible.

Rather than understanding energy as a resource to help society advance, Bataille perceives society as the result of an energy surplus, and a surplus that is explosive and impossible to fully control. Whereas Mumford believes that we might deploy energy in 
better or worse ways to improve our lives, Bataille suggests that the ways in which we deal with energy might not only be simply unproductive, but downright destructive. If his analysis holds any merit, this considerably increases the stakes for a philosophy of energy.

In addition to the significance of energy practices at the global level, Bataille details the implications of his perspective for individuals.

The beings that we are are not given once and for all; they appear designed for an increase of their energy resources. They generally make this increase, beyond mere subsistence, their goal and their reason for being. But with this subordination to increase, the being in question loses its autonomy; it subordinates itself to what it will be in the future, owing to the increase of its resources. In reality, the increase should be situated in relation to the moment in which it will resolve into a pure expenditure. But this is precisely the difficult transition. In fact, it goes against consciousness in the sense that the latter tries to grasp some object of acquisition, something, not the nothing of pure expenditure. It is a question of arriving at the moment when consciousness will cease to be a consciousness of something; in other words, of becoming conscious of the decisive meaning of an instance in which increase (the acquisition of something) will resolve into expenditure; and this will be precisely self-consciousness, that is, a consciousness that henceforth has nothing at its object. (Bataille, 1991 [1949], p. 190).

Bataille here suggests that while efforts towards increasing our energy utilization capacities come naturally, concluding that we should therefore embrace this tendency would be a naturalistic fallacy. Instead, Bataille argues that we should attempt to embrace ourselves as we currently are, with the energy-using capabilities we currently have, and focus on the ways and means of burning off the excesses now available to us. It is precisely in useless expenditure that we find our true selves.

One might conclude that Bataille's sketch of the history of energy consumption bears little resemblance with the present situation. After all, we are not currently trying to expand the energy base of society but rather trying to rid ourselves of the fossil fuel-based portion of it, and thereby shrinking it. Our problem is not that we do not know how to expend uselessly, but that we need to find less polluting resources to do so. When Bataille wrote The accursed share, the finitude of fossil fuels did not seem to be on his radar, let alone the effects of their combustion on the Earth's climate. Arguably, moving away from fossil fuels serves to extend the time before society reaches any limitations as to its capacity for accumulation. 
In Bataille's peak, Alan Stoekl (2007) suggests that we should not disregard Bataille so quickly. Even though Bataille did not foresee the current energy crisis, his perspective remains valuable to elucidate why neither proceeding on the path of ruthless fossil fuel exploitation nor the green perspective of sober frugality provide proper answers to the current situation. The former leads to a problematic build-up of explosive potential that will sooner or later become destructive; the latter does not do justice to our nature (aiming for growth) or our Bataille stipulated potential (aiming for self-consciousness through useless expenditure).

Meanwhile, spokespersons for green technology appeal neither to paths of ruthless fossil fuel exploitation nor to sober frugality. Instead, they tend to sketch Bataillean visions of abundance: "the Earth receives more energy from the Sun each hour than humans use in a year", implying that we simply need to better harness this energy and thereby avoid any such thing as an energy crisis. Bataille's paragraph on the perspective of the individual cited above appears to hold direct relevance to such bold statements. Why exactly would our lives become better should we command an even greater amount of energy?

Both Mumford and Bataille develop critiques against the energy practices of their day agreeing on how energy is not guided towards its proper purpose while disagreeing sharply on just what would constitute that proper usage. Mumford would like to see long-lasting cultural projects (art, architecture) developed and Bataille would like us to simply embrace the burn-off of surplus energy that makes our existence possible. Any attempt at applying the available energy to alternative ends would fail to appreciate the dynamic in which we currently find ourselves.

One other twentieth-century thinker needs addressing in this context. In a quote above, Bataille appeals to our existence as individuals with access to a certain amount of energy. This represents a rather specific perspective on just what forms the human existence, with a similar perspective playing a key role in the writing of Martin Heidegger, for whom human existence changed radically with the advent of modern technology. Heidegger argues that, in modern times, the only way of understanding the world and ourselves is as a "standing-reserve" that is ready to be put to use. Stored energy proves the purest form of this standing-reserve.

Heidegger reaches this insight in his essay "The question concerning technology" (1977 [1954]), in which he searches for the essence of technology. This essence can be found, he holds, in the way that that which is comes into being. In ancient Greece, the process of coming into being was called poiesis, a bringing-forth. This concept served both for that which emerged of its own accord (like a flower) and whatever had a specific creator (a poem, or a tool). Bringing-forth thus represented a particular form of 
"unconcealing" that which was previously concealed, one in which Aristotle's four causes have play. The general process of shifting from concealed to unconcealed was called revealing, from aletheia, veritas in Latin, and now usually translated as truth.

The word technology comes from techne, which is a form of bringing-forth and therefore a way of revealing, and is correspondingly located in the realm of truth. Technology thus reaches beyond a simple means we use to become a fundamental way through which the world emerges before us. One should therefore be able to recognize the four causes in the things that have been brought-forth by technology. However, Heidegger holds that it is impossible to distinguish these causes in the case of modern technology, because technology uses a different form of revealing than bringing-forth.

What is modern technology? It too is a revealing. Only when we allow our attention to rest on this fundamental characteristic does that which is new in modern technology show itself to us (...). The revealing that rules in modern technology is a challenging [Herausfordern], which puts to nature the unreasonable demand that it supply energy that can be extracted and stored as such (Heidegger, 1977 [1954], p. 14).

The tendency of modern technology to store and extract energy on demand features here as a crucial moment in history. It is the central characteristic of a new way of revealing.

Whatever is ordered about in this way has its own standing. We call it the standing-reserve [Bestand]. The word expresses here something more, and something more essential, than mere "stock". The name "standing-reserve" assumes the rank of an inclusive rubric. It designates nothing less than the way in which everything presences that is wrought upon by the challenging revealing. Whatever stands by in the sense of standing-reserve no longer stands over against us as an object (Heidegger, 1977 [1954], p. 17).

From this moment onwards, we cannot but understand a forest as a place that produces wood, a river as hydropower potential, a mountain as a container for ore, and a natural area "as an object on call for inspection by a tour group ordered there by the vacation industry" (p. 16). The very way the world presents itself to us has been changed by this new way of revealing, which Heidegger proceeds to call enframing [Ge-stell].

But how does humanity relate to this enframing? Because modern technology remains a human invention, one might assume we control it or can at least remain outside of its scope, but this does not prove the case. Although we might have put it in place, we have no control over the way of revealing. 
Enframing is the gathering together that belongs to that setting-upon which sets upon man and puts him in position to reveal the real, in the mode of ordering, as standing-reserve. As the one who is challenged forth in this way, man stands within the essential realm of enframing (Heidegger, 1977 [1954], p. 24).

This makes enframing not simply a new form of revealing, but the only form of it available to us while simultaneously threatening to strip us of our humanity as we learn to see one another and ourselves as standing-reserves rather than subjects as well (terms like human resource management spring to mind). Modern technology therefore poses the ultimate danger. The way out and forward into a new form of revealing is unclear, but Heidegger suggests the answer might be found in poetry, which was one and the same as technology to the Greeks: techne.

There is no coincidence behind Heidegger introducing his gloomy vision of modern technology through recourse to energy technologies. As mentioned above, energy is an exceptionally powerful concept for connecting and equating a variety of forms of potential with each other with this potential serving numerous ends. Energy is indeed the perfect standing-reserve. From this perspective, one must conclude that our efforts to move from one energy system to another are hardly significant: these simply represent different ways in which enframing reveals the world to us. Energy, to Heidegger, is no mere means, but also not akin to Bataille's cause of life. Instead, it proves the form through which modern times reveal the world.

We make no claim to be exhaustive as regards these three positions, but merely demonstrate the kinds of perspective that is available once one moves beyond purely utilitarian technological debates. Furthermore, we believe these three thinkers collectively sketch a rudimentary philosophy of energy. 4

What exactly is the value of these perspectives to our project? There are numerous problematic aspects to all of them, and any assessment of their factual correctness (should this prove at all possible) remains beyond the scope of this article. Instead of questioning the correctness of their examples or their historical analyses, we suggest approaching these works as attempts to signify the functioning of energy in society, and therefore, either implicitly or explicitly, sketching a philosophy of energy. In these attempts, we encounter a number of insights with previously hidden aspects of energy practices uncovered or highlighted. How the spectrum of energy technologies available to us expands and might be understood as the extension of evolutionary phenomena, how we increasingly understand everything in terms of stackable resources in our energy-rich society, and so forth.

4. One particular omission we would like to mention is Ivan Illich, who problematizes expanding energy use in relation to equity in society (cf. Illich, 1974). We hope to return to Illich in later work. 
Beyond these insights however, the differences between these approaches raise more fundamental questions. In the first place, at just what level should we understand the relationship between energy and society? Does this relationship change over time and, if so, does the current energy transition entail such a shift?

The inquiry into the natural phenomenon of energy and the critique of energy in society both point to the universal applicability of the concept. Whether from a dammed-up river or a coal bed, energy, its usability, and its functioning in society are understood as one and the same. As seen, this viewpoint leads to insights into energy in general, but it is not very helpful when we look into the dynamics of the current energy transition: if it is all the same, why would new technologies result in a new situation? By focusing on the shared qualities of energy technologies, and talking about the distilled effects of energy in general, these perspectives fail to be sensitive to the peculiarities of specific energy technologies and practices. If our aim is to develop a philosophy of energy that does justice to its complicated workings in our society, as suggested above, we must move away from the general and towards the particular.

This does not mean to say that the general perspective holds no value; rather, we must instead find ways to relate these general insights to distinct practices: to what extent are these practices understood through a general understanding of energy, and to what extent do they distinguish themselves from one another?

\section{AN EMPIRICAL TURN}

A similar problem was recognized in the philosophy of technology in the late twentieth century. Novel technologies like cellular telephones, microbially produced insulin, and communication satellites changed people's lives in very distinct ways, but the classical approaches of Mumford and Heidegger, among others, with their critique of "Technology" with a capital "T", proved of no meaningful assistance. As Verbeek sums it up:

During recent decades, philosophy of technology has increasingly paid attention to the impact of technological artifacts on the lifeworld of human beings (...). As opposed to classical approaches, which were mainly focused on understanding the conditions of "Technology" taken as a monolithic phenomenon, the philosophy of technology has started to approach technology in terms of the actual material objects that help to shape human actions and experiences (2011, p. 6).

This shift has now been understood as an empirical turn in the philosophy of technology (cf. Brey, 2010). From grand critiques on technology in general, attention 
has shifted towards the ways in which particular technologies - say, pre-natal ultrasound or Skype - lead to new moral problems, or new conceptions of proximity.

This focus on artifacts has proved very useful in providing clarification and guidance in an increasingly complicated technological lifeworld. However, in relation to energy technologies, this approach proves less insightful. One reason, as one of us has argued elsewhere (cf. Geerts, 2012), stems from the way the energy aspects of our daily practices tend to get hidden from sight by the artifacts we adopt and use. The computer on which this article has been written is powered by a vast network of natural gas production sites, pipelines, power plants, wind turbines, power lines, load management control rooms, and so forth; but one does not need to know or think about any of this to operate the computer. Precisely because users are not constantly reminded of this complexity, they are able to focus on the task at hand. A philosophical focus on artifacts serves to teach us how little of modern energy practices comes to the surface of daily life, but it is not helpful to get a better perspective on energy technologies.

If artifacts do not constitute the appropriate level of analysis for a philosophy of energy, then just what is? We propose a systems perspective because only at the systemic level can we fruitfully distinguish between different energy practices. Take, for example, two systems for domestic electricity consumption: the standard (inter)national grid, and an off-the-grid solar/battery system. The former is convenient for the user, optimized for efficiency, and opaque, whereas the latter is more cumbersome, possibly less energy efficient, and more transparent. If we simply assume a fixed energy requirement for consumers, the national grid would probably provide the better tool for the job. If, however, we entertain the possibility that these different systems induce different practices, different attitudes towards energy consumption, then the off-the-grid system might be preferable to a national grid in some aspects: it might induce a conscious reduction in consumption, or a rhythm of consumption more closely following the rhythm of the day and the seasons. Furthermore, connecting to the critical perspectives above, a less efficient or more transparent energy system might enable us to look beyond standing-reserves or infinite re-investment.

We are neither making any claim here that this is actually the case, nor taking any position on whether our energy future lies in national or micro grids. To make such claims, a more thorough analysis of these systems and people's attitudes towards them would be necessary. We are merely suggesting that the system level is the appropriate level for performing such analyses. Artifacts obviously play a role in these systems, but by looking at them individually and specifically, we miss the fact they can function differently in different systems. A solar panel can be used both locally (off the grid) and in a large-scale system, but this leads to different practices: off the grid, its power will need to be stored somehow in order to use it when the sun goes down; but, 
within the larger grid, solar panels can be used to a certain degree to decrease the daytime peak load of traditional power plants. Simultaneously, any higher level of analysis, of energy in general, for example, would miss out on the nuances and particularities of specific technologies.

The example above highlights three dimensions to energy systems: convenience, efficiency, and transparency. Many further dimensions can be envisaged: geographic size and shape, load-balancing abilities over time and space, cost per unit of energy, user-reparability, reliance on finite resources, pollution, and so forth. Some dimensions are likely to prove more salient than others. It is the task of a philosophy of energy to compare and contrast different energy systems along those dimensions that allow for the most insightful perspectives.

The focus on systems in this philosophy of energy renders it unmistakably a specific incarnation of a philosophy of technology. Attention goes towards the kind of energy that occupies our technologies, as well as the technologies making this possible. Technologies here must be understood in the broad sense: not simply artifacts, but also societal organizations, "energy culture" and, most centrally, the systems combining all of these factors. How would such an approach work in practice? What kind of insights could it offer? In the final section, we briefly introduce one dimension to energy systems that we would claim generates valuable insights into energy transition developments: the dimension of flux and potentiality.

\section{FluX AND POTENTIALITY}

We have thus far described how a philosophy of energy might help tackle issues in energy transition via conceptual analysis, critical reflection on argumentation, and raising the level of abstraction, while also broadening the playing field by drawing from a range of sources. Although it is difficult to illustrate all these claims within a single example, especially when there is little space to convey its subtleties and nuances, this section aims at taking some preliminary steps in that direction. It problematizes the concept of energy neutrality as the ultimate target for energy transition by emphasizing the importance of temporality in our energy systems.

To introduce this example, we return to the work of Heidegger. In the introduction to Heidegger's work on energy above, we saw that "the revealing that rules in modern technology is a challenging [Herausfordern], putting to nature the unreasonable demand that it supply energy that can be extracted and stored as such" (Heidegger, 1977 [1954], p. 14). The fact that energy is understood as something storable proves essential here. Energy is here patiently waiting; this represents what we propose call- 
ing potentiality, something static that can be put to use at the flick of a switch. It is, for example, the stock of coal next to a power plant, or the reservoir created by a hydropower dam.

Heidegger notes how this is a new phenomenon; it is the merit of modern technology to have access to energy in the form of potentiality: "[b]ut does this not hold true for the old windmill as well? No. Its sails do indeed turn in the wind; they are left entirely to the wind's blowing. But the windmill does not unlock energy from the air currents in order to store it" (p. 14). 5 Energy as conveyed in the example of the traditional windmill, we propose calling flux. This is energy that cannot be extracted and stored as such; thus something elusive, uncontrollable, and flowing.

The crucial difference between flux and potentiality therefore revolves around whether or not humanity controls it. Both a waterwheel placed in a river, and a hydropower dam blocking that river, make use of the potential energy of water flowing to a lower point. However, whereas the waterwheel can only influence the amount of energy taken out of the stream - the river flows whether or not there is a waterwheel placed in it -, the dam enables humanity to let the river flow only when we want to use its energy. In both cases, the river provides flux; but only in the latter case does the river turn into a provider of potentiality. The upshot of this form of control is an increased independence from temporal fluctuations in the energy source: a dam can store water for the dry season whereas the waterwheel becomes useless just as soon as the river stops flowing.

This distinction does not hold only for the primary energy source stage, but rather for every stage in an energy system. Take, for example, an electricity network fed by a coal-fired power plant. The stack of coal next to the power plant is a potentiality, a standing-reserve of chemical energy awaiting combustion in the power plant. When this finally occurs, it becomes flux: first in the form of heat, then as steam pressure, turbine rotation, and electric power. Some forms of flux can be stored and converted into a potentiality again: pressure stored in pressure vessels, electricity in batteries. At every stage in the process, energy is either stored (potentiality) or flowing (flux), but never both. Although flux within the power plant is initiated by human acting, we do not control the flow as such. A certain drop in turbine pressure results in a flow of gas, regardless of whether we are interested in this flow. In order to keep these flows stable and constant, great effort is put into managing pressure drops in the steam cycle and voltage

5 The suggestion that energy as potentiality emerged with modern technology is historically problematic. Peat, stacks of fire wood, and other forms of stored energy (i.e. potentiality) date back much longer, whereas recent technologies like photovoltaic cells and wave power stations must be understood in terms of energy as flux. Additionally, with Mumford, one can say that, although a windmill does not capture energy to store it as such, it does store it as produced flour, ready for consumption by society. 
levels in the electricity network: at every moment in time, the energy input has to match the energy output.

Armed with the twin concepts of flux and potentiality, we turn to the practice of green electricity. This is a product offered by power companies, enabling consumers to purchase electricity produced by wind turbines, photovoltaic cells, hydropower dams, or biomass combustion. Switching from grey to green power is as easy as ticking a box or making a single phone call to the utility company. Because green electricity is not (or hardly) more expensive than traditional electricity and there appear to be no further drawbacks, it seems to be a pain-free solution to becoming part of the solution rather than part of the problem.

How might it be that changing the very source of one's electricity does not seem to involve any physical change but just a simple administrative procedure? This happens because the actual service the utility company provides does not change. It simply continues powering our houses, but now promises to generate as much renewable energy annually as it sells to consumers who have opted for green power. There is no guarantee that the actual electricity one uses is generated renewably; as it is still produced by a continually changing combination of sources to the grid. This scheme allows for the delivery of "green power" even when renewable sources are temporarily unavailable (say, on a windless night), as long as this is made up for at another point in time.

The implicit assumption here is that all electricity is generated equally. It does not matter exactly when or where a $\mathrm{kWh}$ is produced, as its function in the network is not related to its source. Electricity is treated as potentiality: stored energy directed to wherever and whenever needed. The electricity meter in our home patiently accumulates our consumption until periodically getting read and we pay the bill. Although electricity in the network actually is flux, because it needs to be in balance at all times and cannot be stored as such, this misconception might be fine as long as its ultimate source is an easily controlled form of potentiality: measuring electricity as just a proxy for the amount of fossil fuels being burnt to make it. ${ }^{\mathbf{6}}$ However, when fluctuating sources become significant, this becomes problematic. Presently, German renewable electricity is already dumped on neighboring markets on sunny, windy days, because there is no place for it in the national network (cf. Postma, 2012). As we do not control the availability of solar and wind power, there are periods of surplus as well as periods of shortage. Approaching electricity solely as potentiality becomes untenable.

6 This approach is not limited to our treatment of electricity. More generally, the concept of energy neutrality reflects the same focus on potentiality: something is energy neutral when, over its lifetime, it produces as much energy as it consumes. Within, for example, green architecture, it appears to be the pinnacle of developments (cf. Meijer et al., 2011). 
How can society approach electricity as potentiality rather than as flux? We suggest that there are two core reasons. First, the fossil fuels around which our electricity systems are designed are indeed near-perfect forms of energy understood as potentiality. Although there are examples when the flow of fuel stocks (potentiality) was interrupted, leading to temporary energy "famines", the flux component of the global fossil energy system has been relatively unproblematic in the last century or so. Second, the flux-related issues that did occur were always dealt with through technological innovation, hidden away from consumers. In the 1920s, pumped-storage hydropower facilities were already being used to aid coal-fired power plants provide power during peak hours and correspondingly absorbing excess energy when the load on the network was low (cf. Hughes, 1993). Current efforts towards, for example, automatically load-balancing smart grids (cf. Clastres, 2011), or the envisioning of electric cars as distributed storage opportunities (cf. Kempton \& Tomiæ, 2005), continue to distance flux-related energy problems from a broader audience.

For a number of reasons, we do believe that this purely technological approach to dealing with flux in our energy systems becomes problematic. First, and most fundamentally, we would note that the very nature of our primary energy sources is supposed to be changing through energy transition. Whereas fossil fuels function very successfully as potentiality, wind and solar power are forms of flux, fluctuating with daylight, weather patterns, and seasons. Should these sources become the basis of our energy system, load balancing needs to happen on a much larger scale than we currently achieve. That we are already touching on the boundaries becomes clear in the example of the German dumping of excess renewable energy on neighboring markets, and, for example, when technologists assume significant flexibility on the demand side of the energy system when calculating the feasibility of large-scale renewable energy systems (cf. Lund \& Mathiesen, 2009).

This assumed flexibility on the demand side hints at the second problem we raise: this suggests that technological solutions can go a long way, but still need some help from consumers. However, because these consumers have been largely cut off from any appreciation of flux in the energy system, requesting they play their part is no trivial issue. They must first be made aware of this dimension before in any way being expected to act on it. After all, for the consumer, electricity emerges as if a form of potentiality; only when we plug in our appliances does the electricity meter star clocking up consumption. Meanwhile, the proposed technological solutions do little to change this - smart grids act behind their users' backs and give only the impression that fancy software on its own solves the problem.

Finally, the technologist pleas for consumer cooperation also suggests that the actual problem might be solved via different solutions. The issue is not necessarily a 
technical problem of load balancing within the network; rather, it is a question of the compatibility between energy usage by society and the sources and the system providing this energy. The two sides of this system co-evolved to their present situation, and trying to change the production side to accommodate renewable sources while leaving consumption as it is may not just prove extremely difficult, but may also be a solution for a misconceived problem. Another form of energy supply, perhaps one more sensitive to daily and seasonal rhythms, will induce different energy consumption practices. The task for engineers and policymakers is not necessarily to fit renewable sources into the current energy system, but rather to come up with a system that is both sustainable and caters to human needs.

At this point, we have begun questioning the exact nature of the energy transition that was briefly and uncritically introduced at the very beginning of this article. It has become clear that the transition cannot be merely a change of energy inputs, as those inputs have helped shape current energy practices. Which aspects of these practices do we deem most valuable? Only after gaining a better understanding of its functioning can we embark on a properly informed redesign of our energy system. More fundamental questions emerge: can ever-expanding energy consumption be sustainable? To what extent is current consumption merely a result of the structure of energy supply rather than the fulfillment of human needs or wants? What exactly are these human needs for which the energy system should provide? As already noted in the works of Mumford, Bataille, and Heidegger, these questions have no easy answer, but it is equally obvious that they need considering should energy transition prove able to provide us with energy for generations to come.

\section{Conclusion}

In this article, we argue in favor of establishing a philosophy of energy to deal with developments in what is known broadly as the energy transition. A philosophy of energy would be able to explore and clarify the space in which the so-called energy transition is taking place. It can be built upon the work of twentieth century critics of the functioning of energy in society such as Mumford, Bataille, and Heidegger, but not without an empirical turn towards actual energy systems.

We suggest this philosophy of energy would help in tackling issues inherent in energy transition via conceptual analysis, critical reflection on argumentation, and raising the level of abstraction, whilst simultaneously broadening the playing field by drawing on a range of sources. Let us briefly reflect on the treatment of our example in 
section 3 to illustrate these claims. From one of the twentieth century critics of energy in society, we developed two conceptions of energy that allow us to gain insights into the transition in electricity systems. The formerly unproblematic misconception of electricity as potentiality becomes an issue when intermittent renewable sources become more significant in the energy mix. The contrast that the two opposite conceptions provides also shines light on the logic underlying the solutions proposed: as long as users perceive electricity as potentiality, they cannot be expected to change their behavior in order to cope with flux. These are fundamental problems in the current debate that emerge through philosophical analysis. Finally, this approach enables a somewhat wider perspective on the actual problem: what is it that the electricity system is supposed to do anyway?

The example of flux and potentiality demonstrates how a brief philosophical exploration of a rather specific issue to energy transition quickly leads onto fundamental questions regarding the functioning of energy in society. Simply dismissing this result as a case of philosophers problematizing everything would be too easy. These weightier issues were already there but either ignored or answered specifically and implicitly in the current debates and proposed solutions. A philosophy of energy does not complicate the problems needing to be addressed on the path to a renewable energy regime; rather, such a philosophy provides clarifying concepts for tackling some issues while shedding light on problems hitherto hidden as well as the most appropriate paths to the solutions. It is high time to start fleshing it out.

Acknowledgements. An earlier version of this article was presented at the 18th International Conference of the Society for Philosophy and Technology (SPT-2013), Lisbon, Portugal, July 4,-6, 2013. We thank the audience for their helpful comments. We also thank the BioSolarCells research program for funding this project.

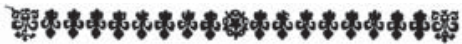


Robert-Jan GeERTS

Philosophy group Wageningen University, the Netherlands. robertjangeerts@gmail.com

Bart Gremmen

Philosophy group Wageningen University, the Netherlands. bart.gremmen@wur.nl

Josette JAGOBS

Philosophy group Wageningen University, the Netherlands. josette.jacobs@wur.nl

\section{Guido Ruiven kam P}

Sociology and Anthropology of Development,

Wageningen University, University for Humanistic Studies, Utrecht, the Netherlands. guido.ruivenkamp@wur.nl

\section{REFERENCES}

Bataille, G. The accursed share. New York: Zone Books, 1991 [194.9].

Brey, P. Philosophy of technology after the empirical turn. Techné: Research in Philosophy and Technology, 14, 1, p. 36-48, 2010.

Ciastres, C. Smart grids: another step towards competition, energy security and climate change objectives. Energy Policy, 39, 9, p. 5399-4,08, 2011.

GeERTS, R. J. Self practices and the experiential gap: An analysis of moral behavior around electricity consumption. Techné: Research in Philosophy and Technology, 16, 2, p. 94-104, 2012.

Heidegger, M. Question concerning technology and other essays. Translation W. Lovitt. New York: Harper Perennial, 1977 [1954].

Hughes, T. P. Networks of power: electrification in Western society, 1880-1930. Baltimore: The Johns Hopkins University Press, 1993.

ILLich, I. Energy and equity. London: Calder/Boyars, 1974.

Kempton, W. \& Tомге, J. Vehicle-to-grid power implementation: from stabilizing the grid to supporting large-scale renewable energy. Journal of Power Sources, 144, 1, p. 280-94, 2005.

Kenn, F. \& Sмith, A. Restructuring energy systems for sustainability? Energy transition policy in the Netherlands. Energy Policy, 36, 11, p. 4,093-103, 2008. 
Lindsay, R. B. The concept of energy and its early historical development. Foundations of Physics, 1, 4, p. 383-93, 1971.

Lund, H. \& Mathiesen, B. V. Energy system analysis of 100\% renewable energy systems. The case of Denmark in years 2030 and 2050. Energy, 34, 5, p. 524,-31, 2009.

MACKaY, D. Sustainable energy: without the hot air. Cambridge: UIT, 2009.

Meijer, M. et al. A next step for sustainable urban design in the Netherlands. Cities, 28, p. 536-44, 2011. Mitcham, C. \& Rolston, J. S. Energy constraints. Science and Engineering Ethics, 19, 2, p. 313-19, 2013.

Mumford, L. Technics and civilization. Chicago/London: The University of Chicago Press, 2010 [1934].

Postma, R. Doe het groen - maar doe het dan wel slim. Interview Lex Hartman. NRC Handelsblad, November, 10, 2012.

Rupp, S. Considering energy: $E=m^{2}=(\text { magic } x \text { culture })^{2}$. In: Strauss, S.; Rupp, S. \& Love, T. (Ed.). Cultures of energy: power, practices, technologies. Walnut Creek: Left Coast Press, 2013. p. 79-95.

Sieferle, R. P. The subterranean forest. Cambridge: White Horse Press, 2010 [1982].

SMIL, V. Energy in nature and society: general energetics of complex systems. Cambridge: The MIT Press, 2008.

SтовкL, A. Bataille's peak energy, religion, and postsustainability. Minneapolis: University of Minnesota Press, 2007 .

Strauss, S.; Rupp, S., \& Love, T. (Ed.). Cultures of energy: power, practices, technologies. Walnut Creek: Left Coast Press, 2013.

Strauss, S. \& Reeser, D. Siting, scale, and social capital: wind energy development in Wyoming. In: Strauss, S.; Rupp, S. \& Love, T. (Ed.). Cultures of energy: power, practices, technologies. Walnut Creek: Left Coast Press, 2013. p. 110-25.

Dongen, H. van. De lotgevallen van energie - Deel 2. Filosofie, 23, 2, p. 34,-9, 2013.

VERBEEK, P.-P. Moralizing technology: understanding and designing the morality of things. Chicago/London: The University of Chicago Press, 2011.

Weinberg, A. M. Can technology replace social engineering? American Behavioral Scientist, 10, 9, p. 7, 1967 .

WrigLEY, E. A. Energy and the English Industrial Revolution. Cambridge: Cambridge University Press, 2010. 